\title{
(C) OPEN ACCESS \\ Walking in rhythm with Deleuze and a dog inside the classroom: being and becoming well and happy together
}

\author{
Donna Carlyle ${ }^{\odot}$
}

Social Work, Education and Community Wellbeing, Northumbria University, Newcastle upon Tyne, UK

\section{Correspondence to}

Donna Carlyle, Social Work, Education and Community Wellbeing, Northumbria University, Newcastle upon Tyne NE1 8ST, UK; Donna.carlyle@northumbria. ac.uk

Received 14 December 2018 Revised 19 February 2019 Accepted 26 March 2019

\section{Check for updates}

(C) Author(s) (or their employer(s)) 2019. Re-use permitted under CC BY-NC. No commercial re-use. See rights and permissions. Published by BMJ.

To cite: Carlyle D.

Med Humanit

2019:45:199-210.

\section{ABSTRACT}

This paper plateau describes children's interspecies relation with a classroom canine, utilising posthumanism, post-structuralism and new materialism as its research paradigm and methodology. Once feelings are cognitised or articulated, their true essence can be lost. Therefore, elucidating moment-to-moment child-dog interactions through the lens of affect theory attempts to materialise the invisible, embodied, 'unthought' and non-conscious experience. Through consideration of Deleuzian concepts such as the 'rhizome' and 'Body-without-Organs' being enacted it illuminates new, 'situated knowledge'. This is explicated and revealed using visual methods with 'data' produced by both, the children and their classroom dog such as photographs and video footage mounted on the dogs harness, from a GoPro micro camera. In addition, individual drawings, artefacts and paintings completed by the children are profound points in the research process, which are referred to as 'plateaus'. These then become emergent as a children's comic book where their relationship with 'Dave', their classroom dog is materialised. Through their interspecies relationship both child and dog exercise agency, coconstitute and transform one another and occupy a space of shared relations and multiple subjectivities. The affectual capacities of both child and dog also cocreate an affective atmosphere and emotional spaces. Through ethnographic, participant observation and the 'researcher's body' as a tool, they visually create illustrations through the sketching of 'etudes' (drawing exercises) to draw forth this embodied experience to reveal multiple lines and entanglements, mapping a landscape of interconnections and relations.

We have two languages: one is words, one is pictures and that is a way of expressing yourself and finding out who you are (Quentin Blake).

\section{INTRODUCTION}

Transforming children's mental health services outlines a key role for schools in supporting children's and young people's social and emotional well-being. ${ }^{1}$ Nevertheless, detailed attention to the benefits of child-animal or child-dog interactions has been somewhat overlooked, despite the growing interest and body of research in the field of anthrozoology and the study of human-animal interactions, with Gee, ${ }^{2}$ Bradshaw $^{3}$ and McCardle et $a l^{4}$ suggesting a need for more qualitative, robust research methods which are longitudinal in design. Scholars such as Gee $e t a l^{5-7}$ have demonstrated that the mere presence of a dog in a classroom can improve children's executive functioning and performance. Yet, the precise mechanisms for this are yet to be known and explicated. This ethnographic (participant observation) and rhizomatic study is an exemplar of doing precisely that to explore, expose, reveal, illuminate and animate these important relational and embodied, interactional processes and mechanisms, seen, heard and sensed through children's perspectives and children's voices. In addition, by being literally 'drawn to see $^{8}$ (through the use of sketches/etudes as embodied process), the ethnographer is engaging aesthetically with the fundamental embodiment and sensory nature of child-dog interactions and experiences through artwork. As Sousanis ${ }^{9}$ exports incredible images and innovative graphic shape-shifting examples in his ground-breaking 'unflattening' project, he dismantles the flatness of sight and its one-dimensional state to open up the multiplicity and potentiality of space, time and experience; 'darting and dancing....animated and teeming with possibilities' (Sousanis p 16). ${ }^{9}$ His emphasis is also on the moving dynamic and mode of sketching between artist embodiment and production of image. This resonates well with artist Klee's idea of a line which 'goes out for a walk' (Klee, p 103) ${ }^{10}$ making the abstract appear multidimensional. As Sousanis (Sousanis, p 75) ${ }^{9}$ so succinctly comments:

By orchestrating the relationship between elements and the space they inhabit, we can trigger correspondence with experience both seen and felt.

This 'unflatterning" approach and two-dimensional viewing of experience through a visual and affective methodology which goes 'beyond text" ${ }^{11}$ is significant; it opens up a greater appreciation of human and non-human relationships in terms of the multiplicity of experience or 'being' and 'becoming' in the world. This allows experience to be viewed as constantly evolving in states of 'flow and flux'.

Deleuze's interest in art and cinema can be taken and reformed as methodological praxis and become what Haraway ${ }^{12}$ refers to 'situated knowledge'- combining theory and social phenomena. Such an exposition enables the production of new knowledge and understanding. Through the animation of Deleuze and Guattari's abstract concepts, they become enactments that explore roles, making them meaningful and tangible, offering an alternative lens with which to view the complex 
mechanisms at play during child-dog interactions within the classroom setting.

\section{Ways of materialising embodied encounters}

Deleuze's perception of vitalism and affect theory enables us to apprehend a more-than-human and posthuman world. He enables a way of seeing the world which accounts for what can go unseen, the affective intensities of experiences which are often felt and sensed, yet can go uncognitised ${ }^{13}$ and therefore unknown. Through affective methods and by drawing on our visceral, corporeal and embodied experiences, we can endeavour to reveal these important aspects of human and non-human wellbeing and flourishing. Interestingly, neuroimagery and neurological flux is not well established in neuroscience research because these images are 'snapshots of a certain moment of physical materiality' (Schmitz and Hoppner, p 5) ${ }^{14}$ which thus, escapes capture as they are more than fixed points in time. In static form, they do not reflect movement and change and can therefore be viewed as neuroreductionist. Although a technological advancement, neuroimages and scans do not allow for the processes and mechanisms of experience to be fully understood and in this sense, experience is 'flattened'. As physicist Barad describes, visually animating and enacting scenes of entangled child-dog relationships can illuminate a mapping of experience which she refers to as 're-configuring space-time-and matter' (Barad, p 179). ${ }^{15}$ Through this 'unflattering' of experience and synthesis of both art and science, we can reveal the dynamic and vibrant relationship between Dave the dog and the Year 6 children.

Through illustration of his concepts such as the rhizome (eg, through pendulum painting), the children develop their affective and visual vocabulary or visual narrative. ${ }^{16}$ This botanical metaphor described by Deleuze and Guattari ${ }^{17}$ can be used creatively in research through Deleuzian action as a data collecting method which allows for the children's consideration of autonomous, unrestricted movement and rhythm. As the rhizome (an underground stem and root system) stretches and freely expands (lines of flight) so too can the children's expression of their experience with Dave in the spaces and places shared within the classroom. These then become 'plateaus'-points of reflection where meaning making is reached and crystallised. These plateaus are visual and textual. They merge and mingle. Rather than thinking of language in itself, Deleuze and Guattari helps us see in pictures and 'images of thought' (Deleuze and Guattari, p 16). ${ }^{17}$

\section{METHODS}

\section{Participants}

This ethnographic, participant observation study was longitudinal, being completed in two phases over a full academic year. The participants were 30 Year 6 boys and girls, aged 9-10 years, their class teacher and school dog, Dave. The children included were from differing cultural backgrounds. The study was carried out in a Northeast of England Primary School with mixed demographics. In the spring of 2015, when the country was in the grip of a General Election, the school decided to teach the children about politics and elections by asking them to form their own political parties. Led by Year 6, each party of children decided what their policies would be and what they would like to see change about their school. The different parties pitched their ideas in assembly to the whole school. Every child in the school was then given a vote, which they popped into a ballet box in a voting booth. The winning party, who pitched to have a school dog, won by a landslide victory. The Head teacher respected the result of the election and set about finding a dog for the school.
After a few weeks, an English springer spaniel puppy, called Dave, joined them. He was 18 months old at the beginning of the research project and he is now 3 years old.

\section{Study design}

Data was collected through multiple means-photographs and short video clips taken by the children with a GoPro camera which they chose to wear on their wrists. Dave also wore the Go Pro Camera on his harness showing his movements and interactions in the classroom setting during lessons. In addition, I documented my observations through fieldwork notes, and I also compiled sketches which I referred to as 'etudes' (drawing exercises) to sharpen my ethnographers gaze and attune me to the sensory and tactile nature of child-dog encounters. Three creative workshops were then introduced, with each lasting for a period of 2 hours. These later became emergent as three interlinked 'plateaus'-which is used in the research to describe points of reflection where meaning making was reached and crystallised.

\section{Walking in rhythm with Dave and the children}

Ideas and concepts can set the rhythm and stride of fieldwork and participant-observation. As Fetterman ${ }^{18}$ posits, developing a rhythm and pace can guide the ethnographic process. This then becomes a strategy, which an ethnographer uses in the setting in order to focus in on the cultural phenomenon of inquiry. The research actions and methods help to also introduce each workshop task, guiding its visual materialisation of how the children explore their interactions with Dave. This enabled the consideration of the underlying mechanisms at play and how the cultural and peer system functioned. The creative workshops were a focal point for commonly shared thoughts and ideas of how the children expressed through both language and pictures, the ways in which they moved and used space within the classroom with Dave. Far from feeling in the role of a researcher/ethnographer, this became a sense of 'kinship' between the children, Dave and ethnographer-participant observer. This enveloped a holistic orientation, creating a whole picture of the culture, with each scene or event being viewed as multifaceted and connected. In this sense, the ethnographer became a human instrument, process mapping the children's and Dave's interactions and encounters.

\section{Data generation and diffraction: flexible and emergent}

The researcher's protocol can be viewed as a map to guide the journey and process. By bringing together affect theory with Deleuzian and Guttiarian ${ }^{17}$ philosophical concepts (such as rhizome and a Body-without-Organs (BwO)) helps to understand how they fit together to produce and reveal new situated knowledge through ethnographic, participant-observation. Such an 'insider' and 'emic' perspective, becoming deeply immersed in the culture, provides a deeper understanding of what the children and Dave do, and why they do it. It draws me to multiple ways of being and 'seeing'.

The intertwining of Deleuzian actions can be seen in the example of the rhizomatic movement involved in pendulum painting (see research protocol: table 1). Such an exposition enables the production-meaning making, new knowledge and understanding. However, it quickly became apparent that I needed to be adaptive and flexible during the creative moments with the children and my research changed in response to the children's requests and conversations with me. In this sense, it was primarily driven by the children and as the workshops and fieldwork progressed, they enacted greater autonomy. This 
Table 1 Research protocol and participant tasks

\begin{tabular}{|c|c|}
\hline \multicolumn{2}{|l|}{ What are we looking for? } \\
\hline Movements & Embodied \\
\hline \multicolumn{2}{|c|}{ What sorts of activity will be consistent with my theoretical framework } \\
\hline Deleuzian actions & What we do? \\
\hline 1. Rhizomatic, nomadic movement (or thinking) & $\begin{array}{l}\text { Mapping, diagramming. } \\
\text { Draw lines to show mapping of walking with dog (and without) using classroom floor-plan. } \\
\text { Pendulum paining or bubble painting. } \\
\text { Stretch, cut, colour, tear, overlay. }\end{array}$ \\
\hline 2. Territorialisation $>$ deterritorialisation & $\begin{array}{l}\text { Marble/ball-bearing paint and box activity. } \\
\text { Use of string, ribbon, wool, or dots to map steps and movements (child and dog) from one } \\
\text { space to another. }\end{array}$ \\
\hline 3. Body-without-Organs & $\begin{array}{l}\text { Mapping child-dog movements. } \\
\text { Drawing and diagramming shared places and space in the classroom. } \\
\text { Use of 'GoPro' 'body cam' to depict lively biogeographical movement of both child and dog }\end{array}$ \\
\hline 4. Smooth and striated spaces & $\begin{array}{l}\text { Show texture of spaces with use of craft materials such as silk fabric, cotton wool, fuzzy } \\
\text { felt, ribbon, foam, polystyrene, plastic (smooth) or beads, sandpaper (striated), glitter, } \\
\text { buttons, corrugated cardboard, bubble wrap. } \\
\text { Make swirls, waves or splashes with craft materials. }\end{array}$ \\
\hline 5. Lines of flight & $\begin{array}{l}\text { Bursts and bolts of energy through splashing, zig-zagging lines and artwork, doodling, } \\
\text { building blocks. } \\
\text { Moments of action like walking, dancing, building, constructing. }\end{array}$ \\
\hline 6. Folds & $\begin{array}{l}\text { Folding of paper. } \\
\text { Folding or bending of craft wire, pipe cleaner to sculpt body or object. }\end{array}$ \\
\hline
\end{tabular}

is evident particularly in workshop three when they envisaged a comic with which to tell their story of having Dave in the classroom with them. This giving of greater autonomy to the children also included use of the GoPro camera, when the class teacher and I were happy to give them control in when and how they used it. In this way, the research became emergent and free flowing, indeed rhizomatic, and generated new lines of inquiry. Through this playfulness with the camera as a research tool, events unfolded spontaneously and any strict adherence to a protocol did not seem pivotal to the overall emergent process.

\section{Workshops}

Plateau \#1 movement: pendulum painting

The first workshop is suggested to the children as a way to explore how they moved around with Dave in the classroom together. Using pendulum painting, it was hoped that the motion of the pendulum (cup and string attached to the authors large camera tripod) swinging back and forth would enact and provoke thoughts of how the children's movements with Dave could visually materialise and map the corporal, affectual and visceral embodied process (figure 1).

These culminated in emergent ideas from the children about our bodies and gravity (curiously their use of creativity and art connecting with science). The use of words 'wild' and 'butterfly' by the children materialise the visual patterns in an important embodied process - a merging of image and text. These artwork activities are not 'capturing' or reducing the children's experiences but clearly depicting how there are multiple subjectivities and multiple truths. They continually move and change and hence are non-representational ${ }^{15}$ (a focus on practices and embodied experiences, prior to conscious thought). Like expansion of space these movements can be considered as globes, bubbles or 'rhizospheres' (Deleuze and Guattari, p 278) ${ }^{17}$ where the child-dog relationship is mutually co-productive in terms of increased agency and spatiality. These vectors of intensity have potentiality and motion. Within these spaces new ways of interacting are emergent. The attunment, rhythm and tone (or musicality) ${ }^{19}$ of their moving bodies afford close physical contact.
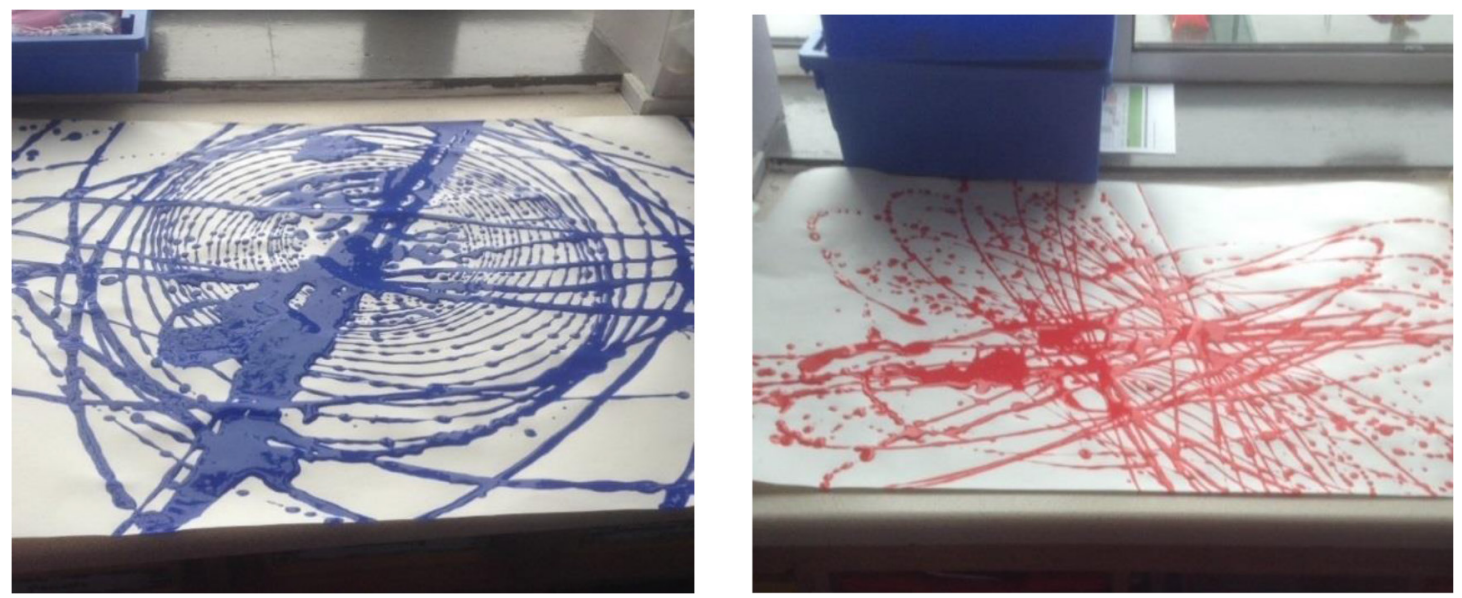

Figure 1 Pendulum painting producing movement that is 'wild', 'a butterfly' and has 'gravity'. 

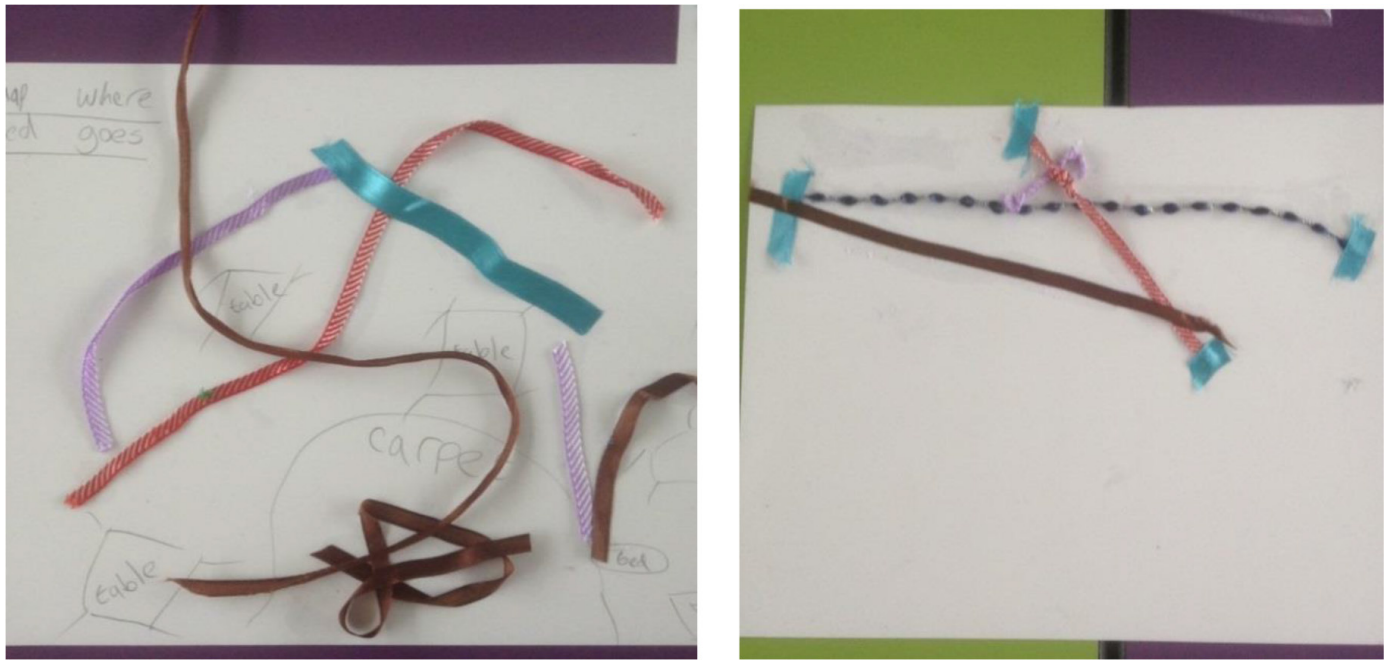

Figure 2 Wool and lace craftwork showing how Dave the dog 'makes pathways to connect us'.

The moments of intricate and intimate touching and stroking occurring in a 'smooth' space (unregulated) which is safe and part of the classroom (sub) culture. The classroom also becomes a 'sensoryscape' of relational encounters and events. These assemblages of well-being are ones in which affective sensitivities collide through relational dominions which are embodied and transforming. The following extract from field note assemblages highlights this dynamically and wonderfully in the teacher's reflections and comments:

Extract from field note assemblage 11/07/2017 (Observation 10):

Because of Dave I have become a very popular teacher; I stroke and hug the children, just like I do with Dave. I stroked Billy's head last week when he was crying and upset, it's like I am an extension of Dave and he's helped me feel able to comfort them through touch or a hug, when this is often not seen as 'politically correct.

Deleuzian attention to creative processes, as well as being deconstructive, allows for the consideration of the affective dimensions of the classroom atmosphere and environment, given its relevance to fruitful learning.

\section{Plateau \#2 space(s): craftwork}

Workshop 2 entailed the children selecting whichever medium they wished to show their favourite places and spaces they shared with Dave in the classroom. Materials such as fuzzy felt, feathers, cotton, string, lace, craft wire, buttons, pegs, straws, tissue paper, cloth, sandpaper, etc were made available. Some of the children used string and lace to described how 'Dave makes pathways that connect us' (see figure 2). Dave would initiate many of these 'pathways' through his 'rhizomatic' ball game, in which he would roll his ball back and forth between the children. This had a notable element of communication, with some of the children whose first language was not English, using this game to engage with other children and connect with them in a non-verbal manner.

Sitting on the classroom carpet became a point of reflection in the children's pictures, a space where they would regularly sit and join Dave, either during lessons or outside lesson time. This space enabled feelings of playfulness, a becoming-with, a becoming-together of Dave and the children. As Deleuze and Guattrai $^{17}$ purport, these movements, flows and affects are relative to mutual well-being and feelings of self-control. Dave then affords movement, freedom, control, motivation, enthusiasm, participation and more choices, as denoted by Ryan and Deci, ${ }^{20}$ as important attributes which enhance well-being and self-determination.

Some of the children used craft wire which was shaped into 'bundles' and described by them as 'bundles of love' (curiously emblematic of a tuber/root system) or Dave and child/children entwined together (figure 3).

Several of the children decided to use other mediums and draw or sketch with pencil or crayon. Jenny drew two pictures alongside one another, one in which the landscape looks sad and gloomy, then the other which is happy and colourful (when Dave is in the space). Some of her classmates referred to this as a 'comic strip' and a couple of boys fetched their marvel comic books from their drawers to share with me. They then collectively decided that a comic book would be a good idea through which they could tell their story of being with Dave in the classroom. The third plateau was then emergent as a 'rhizo-comic' (figure 4).

\section{Plateau \#3 being and (be)coming together: photo assemblage and emergent children's comic}

The third workshop was introduced through the idea the children had of making a comic to tell their story about when they came together with Dave (figure 5).

The children accumulated over 300 photographs they had taken of which 50 were selected for the workshop and consequent third plateau 'being and (be)coming together'. The 50 photographs were assigned to five table-top assemblages. The children, with Dave alongside them, then laid them out in panels on a large piece of paper, in any sequence or order they wished. They then added speech and thought bubbles as well as shapes, colour and captions to tell their comic story. Once all the photographs were collated, the pages were brought together 'rhizomatically' (non-linear, non-hierarchical, dis-organised) culminating in the completed comic. The children also voted to rename Dave as 'Tails' and agreed the title 'The Terrific Tale of Tails! An amazing School Dog' for the emergent comic. This 'othering' of Dave being renamed as 'Tails' further exemplifies how he was given an alternate role and deterritorialised (liberated from the structure and order of the classroom system). In doing so, the children could also be viewed as becoming deterritorialised themselves, freeing them up from being 'pupils', to becoming creative storytellers and nomadic explorers. This 

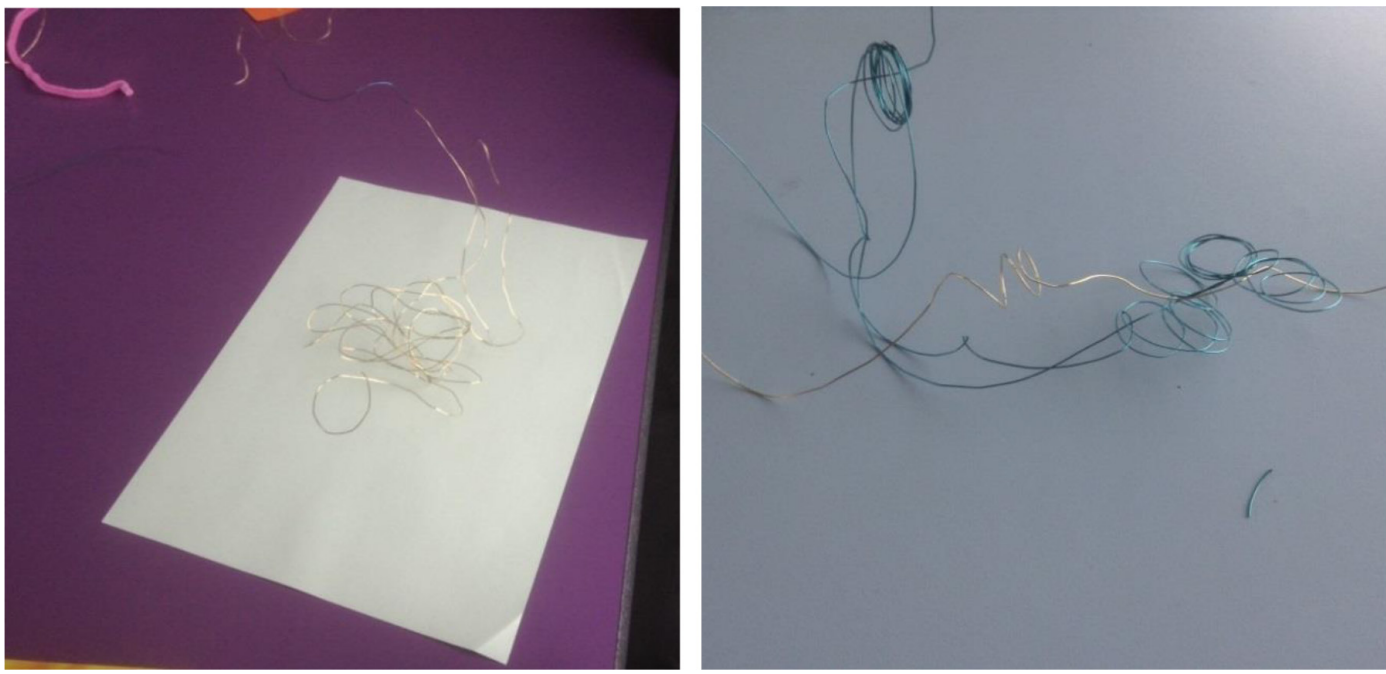

Figure 3 Bendy craft wire depicting 'a bundle of love' and 'Dave and me'.

material-semiotic process illuminated the children's affective encounters with Dave, making visible the invisible (the transmission of affect), non-conscious, unthought, sensory elements which are grounded in Deleuzian actions and concepts. This enabled a two-dimensional 'unflattening' of the experience to see and view the surface below the experience which is 'teeming with possibilities' (Sousanis, p 16). ${ }^{9}$

\section{Enacting scenes of entanglement through a 'rhizomorphic' comic}

The children and Dave becoming a Bw0

One of Deleuze and Guattari's ${ }^{17}$ lexicons is the concept of a BwO. This inimitable idea offers a way of seeing how relationships can become subject to societal structures of organisation. It is a surface (philosophically), not a physical body, where social energies interact. Far from it conjuring up any idea of an 'embryonic' state, it is emblematic of the need for agency and autonomy to be acknowledged in childhood (and animalhood for that matter), thus, challenging the 'striations of space by the State' (Luhssier, p 45) ${ }^{21}$ and social construction of children in particular, as requiring control and regulation. It provides a way in which to experiment and enact experiences in the world and how they are constantly being rewritten and changing. Hence, Deleuze and Guattrai's BwO being in opposition to the 'territorialisation' and deliberation of the body. Our ethics of care towards children and animals means by 'becoming together' in multispecies relations and entanglements we must reconfigure non-human relationships and give their significance greater attention. Through such rhizomatic thinking, we can become well together and flourish alongside one another. The children's and Dave's rhizocomic shows such a dynamic and exemplifies the rhythms of affect which ultimately expand our understanding of the significance of animal-human relationships, Tim Edensor (2010) This co-creation between the children and Dave reveals a distinct relationship in which spaces are shared equally and disrupted dynamically from being territorialised to becoming deterritorialised. As we can see in the pictures, the children and Dave share "common worlds" 22 where they both co-exist in the classroom together and enjoy an egalitarian relationship on the same level quite literally (becoming an assemblage sitting on the floor together, and Dave's body sharing chairs and tables (see comic panels B and D in figure 6). As Donna Haraway states 'learning how to flourish together in difference' (Haraway, p 301$)^{23}$ being exemplified. This difference is a non-human difference with Dave enabling a non-human relationship that is fundamentally sensorial in nature (tactile, visual, olfactory and auditory) and equal. Through his material, unboundaried body Dave avails himself for touch. Detailed observations and etudes

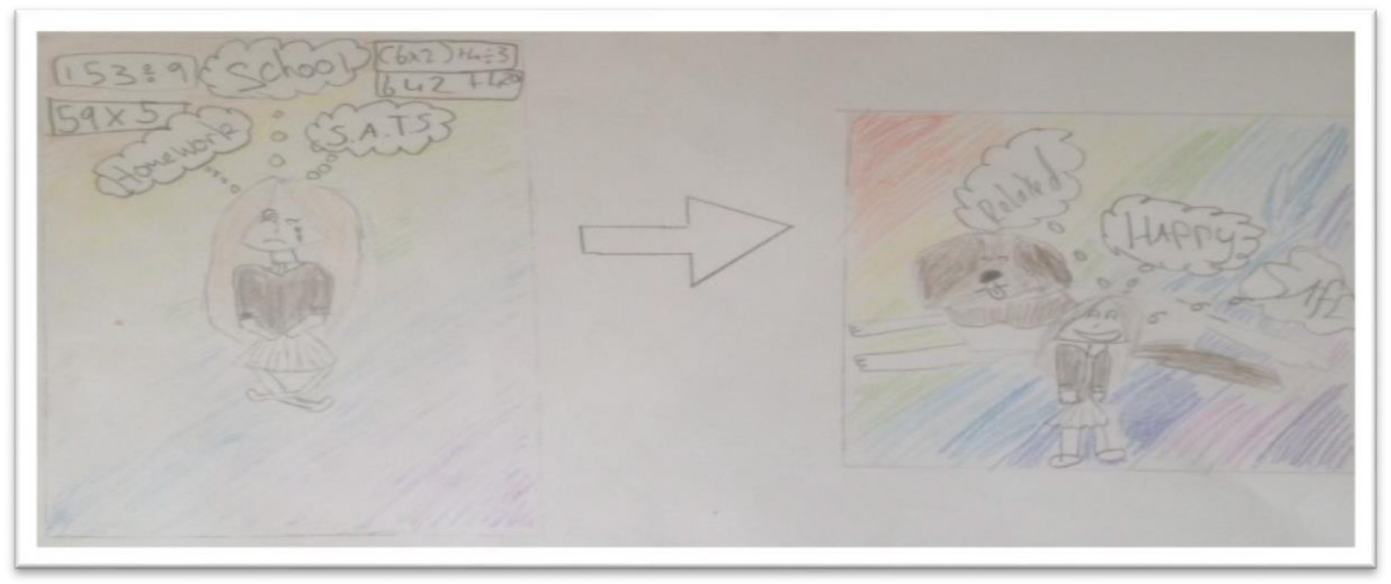

Figure 4 Jenny's 'comic strip' as an emergent process: when Dave is shown in the panel the rainbow is more vibrant and colourful, changing a state of crying to becoming 'relaxed', 'happy' and 'safe'. 


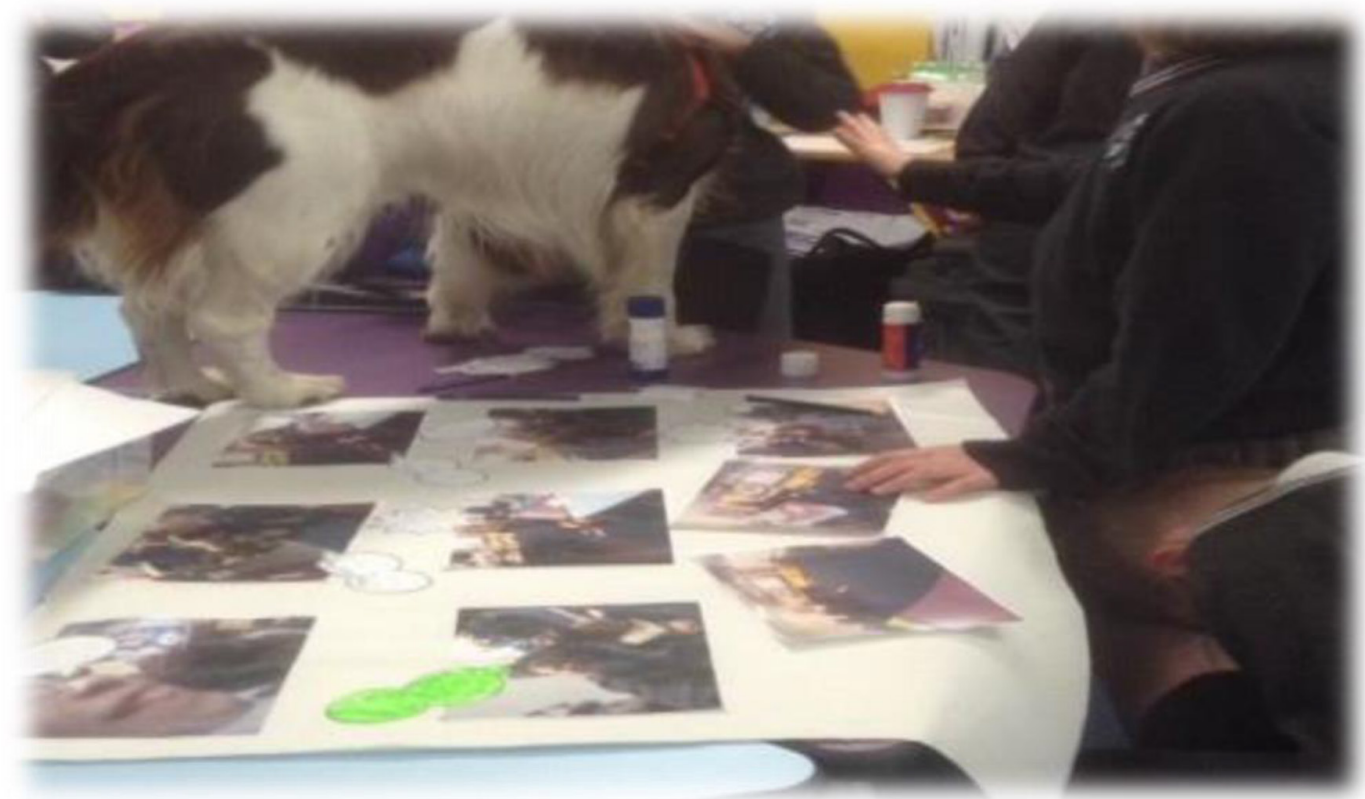

Figure 5 Photographic 'deterritorialised' assemblage as children's comic.

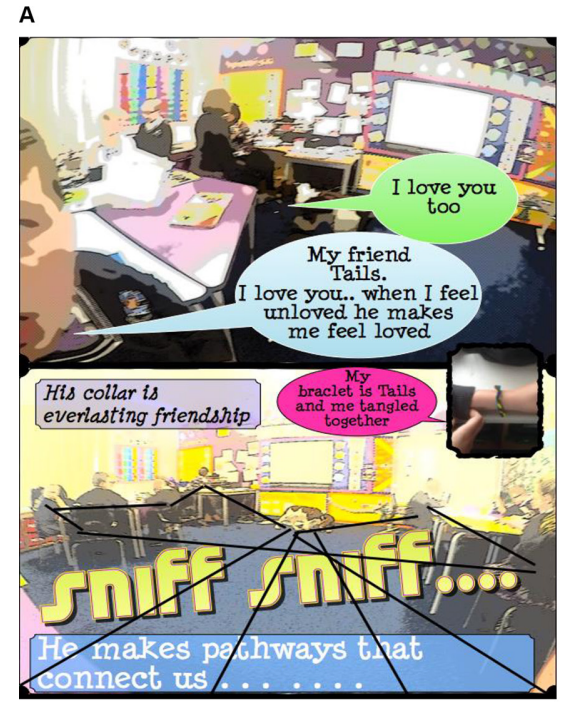

C

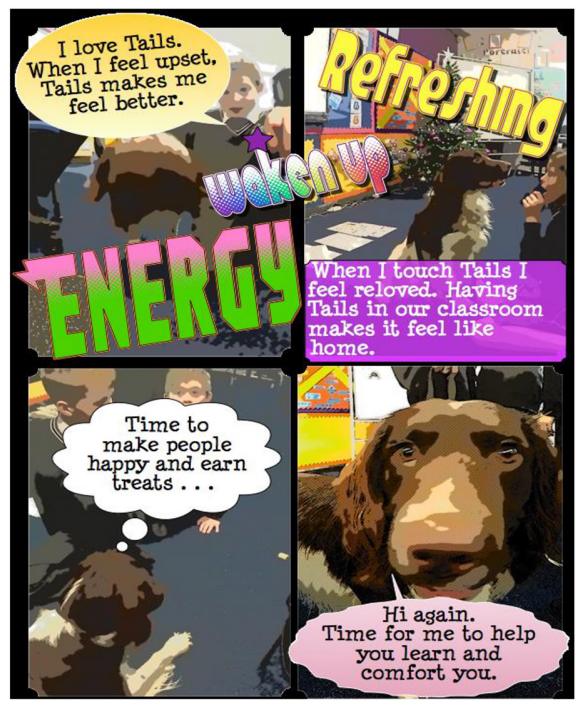

B
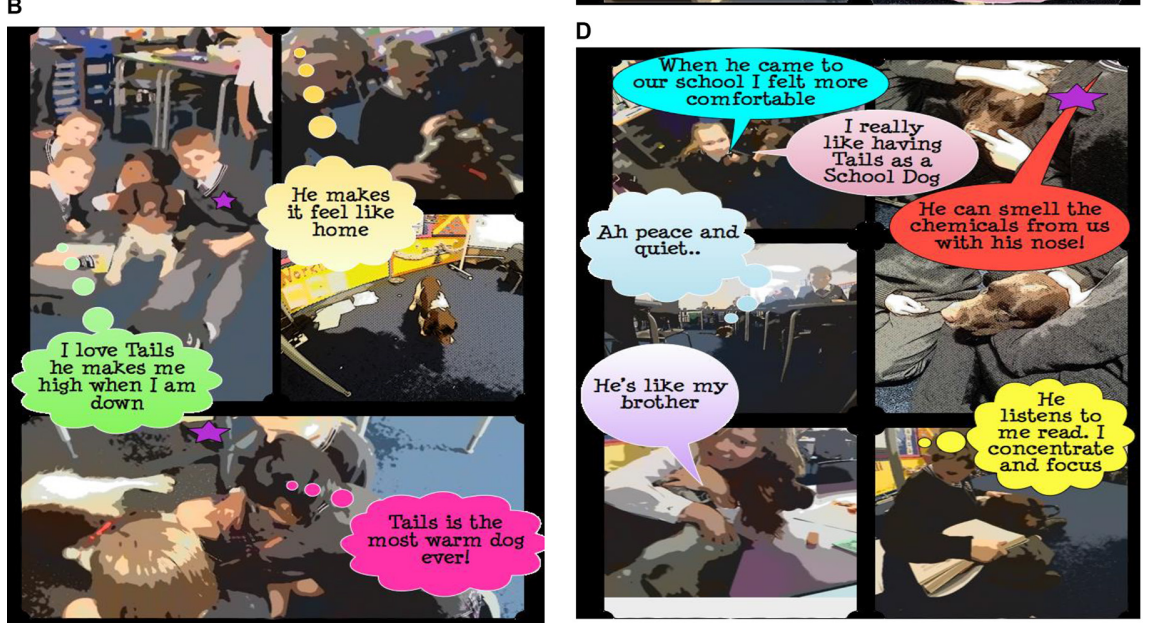

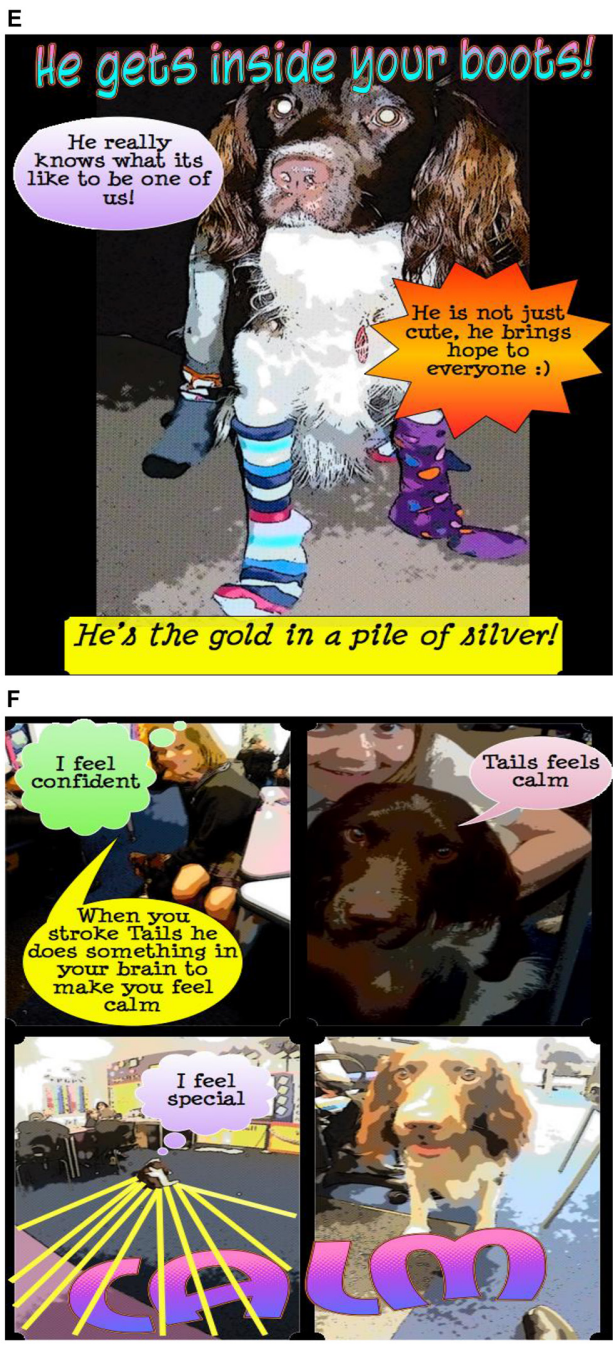

Figure 6 Comic panels A-F. 
revealed that these touches were carried out in varying, intricate ways, either patting, stroking or massaging the contours of his body. His ears and face were regularly stroked rhythmically, much to Dave's delight! Eye contact was also a noteworthy feature of interactions where Dave and the children mutually gazed at one another for sustained moments during physical contact. This interesting aspect of their close relatedness through Dave allowing them safe permission to touch, clearly showed a mutual sense of connectedness, which is essential not only to the children's enhancement of sensory and perceptual awareness but also of their shared sense of well-being and flourishing.

Closely observed hand movements, animated through the researcher's etudes, on Dave's body showed varying ways in which the children used his body and fur in a rhythmical and regulatory way. Children's fingers and hands would circle, flick, sweep, scratch, tap, ruffle and flounce Dave's body fur, limbs, muzzle or ears. This orchestration of movement resembled what the author considered to be like 'piano fingers'-the children's fingers lightly touching and pressing Dave's body as if it was a musical keyboard. The hand patting also became reminiscent of gently tapping motions, like percussion and beating on a bongo drum.

In addition, Dave in becoming part of the children's material culture is affording ${ }^{24}$ the children more spaces and more places for becoming agentic, autonomous, competent and powerful. Such a position is referred to as 'emplacement' by Pink (p 62) in her personification of the value in sensory ethnographic (affective) methodologies and how our sense of emplacement continually shifts and changes through embodied and sensory ways of knowing and learning. Thus, the children state how Dave makes the classroom 'feel like home' (see comic panels B and $\mathrm{C}$ in figure 6) and how such material, multisensory memories, evoke and play a part in changing and transforming the atmosphere and structured, authoritarian power of the classroom environment.

It is an unfolding companionship between the children and Dave in a process of 'becoming-liberated' and being-well-together during challenging times (such as SATS) when touching and stroking of Dave occurs in rhythms of movement and sensory engagement. These 'striated' spaces are made 'smooth' and nomadic, with the nomad (Dave) and the children inhabiting this space and not attempting to dominate it but expand its energy and rhythm. These striations are aspects of the territorialisation of the classroom landscape, which is structured, laden with order, power, and control. Indeed, the researcher's own body became nomadic and hybrid, as they regularly negotiated their researcher-ethnographer-explorer-learner-becoming-native (participant-observer) roles. My being and becoming nomadic researcher, similar to Dave, resonates in the following extract from the researcher's field note assemblage, in which they became an embodiment of Dave.

Extract from field note assemblage 27/10/2017 (Observation 25):

As I am sketching my observations, Billy, who is sitting next to me, reaches out, smiles broadly and strokes my arm then rubs circles on my back saying, "you are Dave." In that moment, I feel profoundly aware of my physical presence in the classroom and how I seem to embody Dave. As an ethnographer, this was not only amazing in terms of my 'position'-becoming an egalitarian figure in my relationship with Billy, but how I seem to have truly become an instrument and 'tool' in the research process through my apparent 'embodiment' of/as Dave. I feel very humbled and moved, but more so very connected to Billy. I smile back at him and respond by also stroking his arm. The teacher's previous comments now resonate loudly in my head, that she too has felt like an 'extension' of Dave and how he affords her 'permission' to touch the children 'safely'. I can appreciate fully how the teacher (and now myself) experiences this as a natural encounter and how Dave is affording a different kind of relationship with others in the classroom. It feels hugely monumental.

Understanding the researcher's own responses as 'enactments' as well as the children's, which are contained in both our bodies, then mediated through a social field, provides dynamic moments of 'affective attuning' (Cho, p 24 and 33$)^{26}$ producing affective moments in which the data 'glows' (Knudsen and Stage, $\mathrm{p} 7$ ) $^{27}$ and resonates. These are the non-narrative, unspoken aspects of knowing through the rhythm and tone between bodies within the classroom environment.

Moving diffractively between the artwork and GoPro photographs, in a meandering, rambling motion (considering the camera neither deflecting or reflecting reality), the researcher refers to as making 'plateaus' and creates a diffractive anal$\mathrm{ysis}^{12}{ }^{15}$ (breaking apart and reconfiguring). This diffuses the affective encounters being explored; thereby creating new formulations, patterns and understanding through incorporation of the researcher's mutual embodiment and entanglement in the process. Thus, moving and weaving through the data in a non-representational way, ${ }^{28}$ avoiding any codification and stratification of the 'data', allowing it to remain emergent and in a constant state of change and 'becoming'. This encapsulates the researcher body as 'tool' and 'instrument', magnifying the compelling nature of embodied processes. The key aspect of the consideration of the researcher 'body' as part of participant observations allowed them to feel and see in more depth what unfolded in the intimate encounters between Dave and the children, and Dave and ethnographer. The ethnographer's embodiment in the experience enables a deep immersion in the experience and revealed rich data in itself, in order to consider and show the affective mechanisms and sensorial aspects involved in child-dog interactions. In operationalising the idea of the researcher's body becoming a BwO' similar to Dave, they moved in a nomadic way around the classroom, deterritorialised and liberated. However, there are times we both inevitably return to being territorialised and it is this state of oscillation between the two, which opens up spaces of becoming other, breaking boundaries with the authoritarian, ruling, structured and organised environment. Importantly, these spaces are transitional, which then enable alternative ways of being and becoming together. The children becoming something more than a 'learner' who takes in knowledge, and Dave becoming something other than a school dog to a character in a comic with a mind and voice of his own. He is given a 'comic hero' type of status, therefore not being considered as a Pets as Therapy dog, assistance dog, emotional support dog or even a pet, but a friend and supporter. As Haraway $(\mathrm{p} 7)^{23}$ has previously asked 'whom I touch when I touch a dog' is a question the author has contemplated many times as an ethnographer. Touch can be soothing, rhythmic and self-regulatory. In this study, when Dave is touched and stroked by the children, he affords them something more such as the role of playmate (ball games, tummy rubs, chase and fetch) and friend. As Buchanan ${ }^{29}$ purports he also becomes a 'converter' of the social assemblage when he comes together with the children. This 'converter' means he disrupts and transforms the classroom environment and atmosphere, becoming space-maker and disrupting operations of power. This expansion of space within the classroom reflects both human and non-human agency and how child-dog interaction is mutually co-constitutive and deterritorialising (liberation from the usual boundaries and structures 


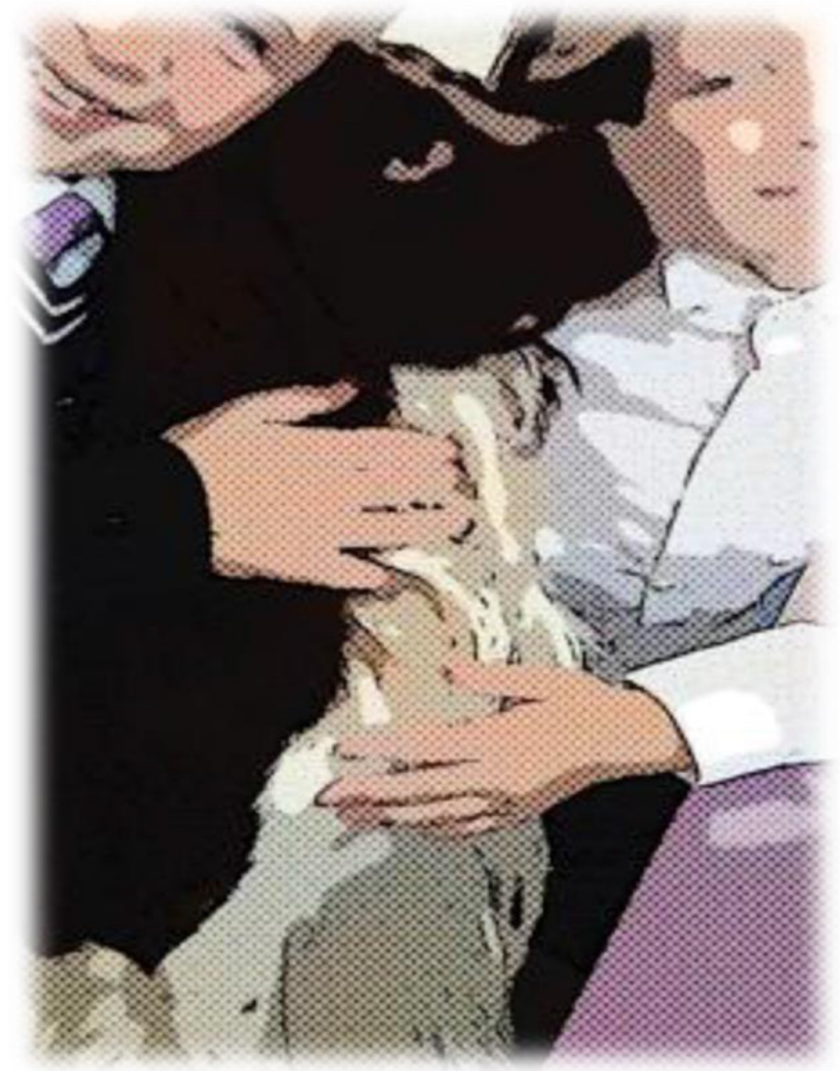

Figure 7 Pixilation of the children's photographs: emergence of the affective elements of Dave's presence show in smiling 'beaming' faces.

of the classroom routine). This includes the development of new subjectivities and new modes of embodiment for the children. This is also revealed in quotes from the children such as 'be gets inside your boots' (see comic panel D in figure 6) the children animating Dave's capacity for empathy, bringing it to life that which may otherwise be lost in purely intertextual methods.

On completion of the comic, the children were asked to make any comments on their artwork. One over-riding and recurring expression from nearly all of the children was that Dave made them feel 'happy'. The deterritorialising potential in the BwO allegory translates into a sense of well-being that could not be apprehended by more concretised measures. It then escapes any bio-medical discourse and territorialisation within the territory-classroom setting. This is then not confined to the reductionist codification, classification and stratification of human-animal interactional measures, ensuring affective experience is augmented. The happiness that the ethnographer witnessed and was 'drawn to see' could be seen and emotionally felt through the children's glowing faces and beaming smiles. The ethnographer felt it too, as a warmth in their body and relaxation of tension in their neck, shoulders, arms and legs. It can also be seen and felt through the reading and viewing of the comic panels in the process of pixilating the images and 'lit up' faces (figure 7), thereby connecting us more profoundly with the corporeal, embodied and aesthetic nature of the experience. The comic panels $\mathrm{C}$ and $\mathrm{E}$ (figure 6) reflect something similar in which the children use image and text to show us the sensations and states which can emanate and radiate from bodies; yellow lines emanating from Dave's body and the use of yellow with the word 'refreshing' (figure 6).
As Hague, ${ }^{30}$ highlights, 'reading a comic is not just a visual process it is a multi-sensory experience', (Hague, p 25) ) $^{30}$ and we are drawn to look at the sensorial elements, that is, the tactile and affective actions shown through the pixilated images. Ultimately, the comic is therefore able to convey a visual narrative which text alone would omit. This method is then a powerful affective tool as opposed to mere conversational and interview approaches to data collection, due to its unique embodied nature. Scott $\mathrm{McCloud}^{31}$ provides an intriguing perspective on the use of panels. He expands:

Comic panels fracture both time and space, offering a jagged, staccato rhythm of unconnected moments. But closure allows us to connect these moments and mentally construct a continuous, unified reality (McCloud, p 67). ${ }^{31}$

In that sense McCloud's assertion aligns very well with the ethnographer's diffractive methodology and approach to the 'data' analysis. This is also in keeping with Thrift's idea of non-representation, and Deleuzian concept of rhizomatic thinking.

The 'happiness' that Dave gives the children could be seen as an affective embodied, reciprocal encounter, not just as a result of their biophilia, or an innate need to connect with nature. Importantly, Dave is not passive, subordinate or boundaried entirely. He is free to roam and wander, avail himself to the children, initiate his rhizomatic ball game or 'tummy rubs' through his charismatic and cute 'springer sprawl'. His physical bodily presence is a palpable part of the classroom rhythm and tone(James Ash, 2013). This is a significant consideration with regard to the place of multispecies relationships in childhood and how they have potential effects on well-being and flourishing, see Timmy and Dave 'snuggling in' together, etude 13 (figure 8). Given that children in the UK are considered less happy than many of our western counterparts, ${ }^{32}$ this is very pertinent in terms of enhancing children's social and emotional well-being.

\section{RESULTS/FINDINGS}

The 'experiments' in which the children are exploring their encounters (intra-actions) and relationship with 'Dave' is dynamically produced, allowing an unfolding of narrative that is described by several of the children as 'wild' (figure 1) a destratifying process as it were-a co-constitution and

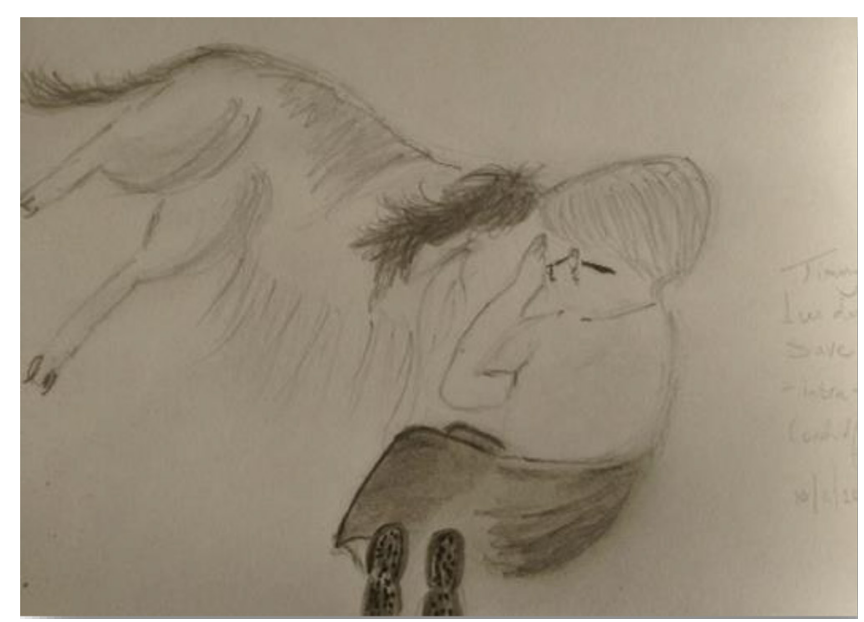

Figure 8 Etude 13: Timmy and Dave mutually co-constituting one another through touch and 'snuggling in'. 
transformative experience for both child and dog. These are shared moments in which Dave was equally as animated as the children, almost participating in the painting with his paws stepping in and around the canvas. This in itself becomes the 'refrain', a map of an event fitting together functionally, a setting-off of a rhizome, lines of flight, a breaking free from the flattening of stratification. This marking of territory, produces regularity and repeated, changing patterns of sound, place and space. It therefore becomes an affective space feeling 'like home', an affective atmosphere and a sensoryscape, through its movement in the constitution of a territory. As McCormack $(\mathrm{p} 55)^{33}$ illuminates:

bodies have the potential to generate spaces in the process of their movement...moving bodies have an animating quality inextricable from space and time

This flow of connectivity between bodies knows no boundaries or restrictions during the deterritorialisation of space. Therein lies a transformative aspect where Dave is seen as not just 'cute' but providing a sense of 'hope' (see comic panel E in figure 6). Thus, the child-canine assemblage enables children to move from one state of being to another, for example, low to high, sad to happy (see comic panel B in figure 6). He is an assemblage converter, which changes emotional states and emotional atmospheres.

In paying attention to these affective moments as events, the 'data' appears to glow and shine, and thus takes on much greater significance.

Rhizomatic rhythms matter a great deal to our understanding of affect, animal-human relationships and well-being. The three emergent paper plateaus show how the children helped to co-create an affective experience with Dave and highlight the distinct relationship developed between children, Dave and researcher-participant observer-ethnographer.

These connective assemblages fundamentally afford touching, social bonding and communication between the children and Dave, thereby enhancing well-being and flourishing across human and non-human multispecies relationships

\section{DISCUSSION}

As animals, particularly dogs (including 'school' dogs) seem to be an increasing part of children's family life and material culture, it is important that settings ensure an ethic of care framework ${ }^{34}$ which encompasses and acknowledges both children's and dog's agency. Both have a voice and a need to become more 'visible' in the spaces and places they inhabit to ensure their ongoing growth of competence, autonomy and relatedness. This links with the children developing a eudaimonic sense of well-being through the care-giving behaviours that Dave activates in them, and their acquisition of virtuous and moral behaviours that strengthen their character. Its bidirectionality enables a mutual flourishing, being and becoming well together. This attuned relationship moves beyond hedonistic desire or pleasure as Dave's vitality and energy - 'thing power' (Bennett, p 18) ${ }^{35}$ permeated the rhythm and tone of all inhabitants inside the classroom. ${ }^{36}$ The collective nurturing (of both Dave for the children and the children for Dave) witnessed in the classroom materialised regularly in the ethnographer's sketches/etudes. This patterning of affects, movement and interaction is embodied and vibrant. As Deleuze and Guattari ${ }^{17}$ assert, these are relative to the ideas of what constitute well-being.

Child and canine bodies should not be viewed as passive and subordinate. Each affords the other a multispecies relationship which is mutually co-constituting and transformative (through touch and sensory processing) to one another's sense of wellbeing and happiness. For example, the deep muscle pressure that Dave and the children provide for one another, during 'snuggling in' together, seen in etude 13 (figure 8) and the warmth, softness and sensation of weight and pressure from one another's body is calming and emotionally regulating both their shared states of mutual becoming's.

Dave's gentle breathing and snoring involve differing vibrations, which also have a regulatory, rhythmic and synchronistic quality from body to body. This tactile and embodied process seems to be both comforting and enriching for both the children and their teacher, in increasing their capacity for both verbal and non-verbal communication, through visceral and kinaesthetic ways of being and knowing. This mode of connecting and creation of 'pathways' for interacting is significant and visually materialised in figure 2 . The author also recalls being physically and emotionally regulated and contained from the sensation of deep muscle pressure, particularly during times of change and uncertainty, when Dave would rest his head on their feet. His warm touch and presence infusing and shifting their bodily state. The following field note extract features this corporeal experience.

Extract from Field note assemblage 22/05/2017 (Observation15):

As I become more aware of my own bodily sensations the gentle pressure on my feet from Dave is somehow making me feel grounded and connected to everything around me. It reminds me of the important function of 'swaddling' a baby and how the light sheet 'holds' themnot only just physically but emotionally. It's like Dave is providing me with the same sense of a 'holding and containing' environment and a 'second skin' to comfort and sooth me. The children often sit with Dave, looking as if both their bodies have 'merged' and I now see this in a very different sensory way. It feels an important function of Dave in the class, and how he affords these moments of security and well-being.

Professionals across multiple setting such as hospitals, clinics, schools and even the family home are all spaces and places in which human and non-human cultures and relationships are enacted and subject to varying rules, regulations (territorialisation) control and dependency. This study can consider how children's bodies and animal's bodies can be reconfigured as BwO's. This study exemplifies and challenges visually, how institutional power dynamics are played out and altered by the child-dog assemblage(s) (figure 6) showing examples of where power is negotiated and shared between Dave and children, for example, sitting on the floor, sharing a chair or desk, going beyond designated 'lines' and 'boundaries' together.

There is a spatiality to well-being, a bubbling and expansion of spaces and places of transition for children to become playful vectors, connected to one another and Dave through their innate desire for human and human-animal relationships and encounters, which extend beyond cute, cuddly charisma. Organisations can then give animals a 'voice', making them 'visible' and part of an ethic of care ${ }^{34}$ that is beneficial for both human and non-human in becoming and being well together.

\section{CONCLUSION}

Gallacher and Gallagher ${ }^{37}$ argue that researchers must have methodological 'immaturity' as a means to fully include children's voices and participation in research; children being active rather than passive. The interesting choice of the genre and medium of a comic creation by the children could be an exemplar of my allegiance and adaption to this 'immaturity', 


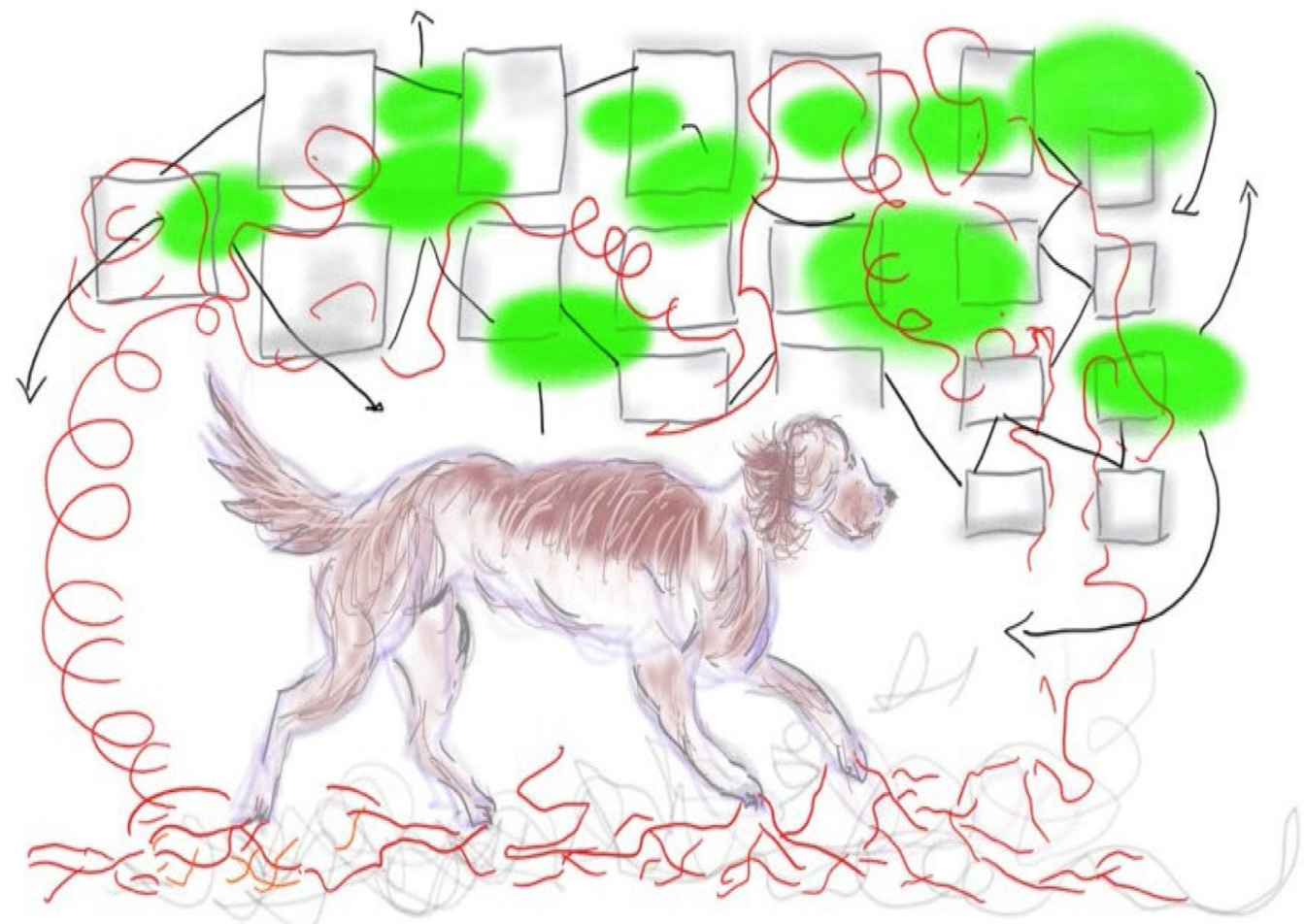

Figure 9 Etude 6: Rhizomatic Dave the dog, creating social assemblages and rhizospheres.

enabling the children's performative (doing things themselves) production in which both their voice and in part, Dave's voice is heard.

In addition, by including Dave as a methodological axis of difference in the research offers a potential mechanism to understand and redress forms of human exceptionalism. In his embodied canine form, he produces movement (and non-human data) differently, altering our perspective of space and time. This involved filming child-animal action (use of a GoPro micro-camera attached to Dave's harness), agency (affect) and reconsidering Dave's role in social/human life. This 'canine-cam' generation of data quite literally helps us see things through a non-human lens. His lively biogeography and non-human charisma animated in action. ${ }^{38}$ What is evident is Dave's appeal clearly extending beyond 'non-human charisma' of being cute and cuddlyJamie Lorimer (2007). As the children show through their comic, Dave is a sentient being with an 'animal mind' and this corresponds with current research findings by Menor-Campos et $a l^{39}$ with Spanish Primary School children. This study also amplifies, both visually and materially, how Dave and the children create and re-enact 'contact zones' (Haraway, p 4) ${ }^{23}$ which open up spaces of shared becoming's and multiple subjectivities. These can also be considered as rizospheres and social assemblages created through Dave's nomadic and rhizomatic movement, etude 6 (figure 9).

This study's rhizomatic format is one, which crosses the lines between different types of disciplines, and it can make connections across several modes of being (biological and social domains can be compared and connected through a process model). It therefore offers an innovative lens with which to view and understand the nuanced mechanisms of child-dog relationships and their shared spaces and places of well-being and flourishing. In the present climate that has seen a rise in therapeutic education, where therapeutic training programmes are becoming part of children's 'curricula' in schools, this study stands out rather distinctly. The role of Dave as nomadic explorer, friend and companion, clearly opens up spaces for childhood agency and flourishing-through his becoming a comic 'crusader' Dave has metamorphosed into is a champion for children's well-being. His own well-being and flourishing is emergent alongside them, bringing together common worlds for improved learning communities.

Contributors DC is responsible and accountable for the content.

Funding This study was funded by Northumbria University (7100035676).

Competing interests None declared.

Patient consent for publication Obtained.

Ethics approval Northumbria University.

Provenance and peer review Not commissioned; externally peer reviewed.

Open access This is an open access article distributed in accordance with the Creative Commons Attribution Non Commercial (CC BY-NC 4.0) license, which permits others to distribute, remix, adapt, build upon this work non-commercially, and license their derivative works on different terms, provided the original work is properly cited, appropriate credit is given, any changes made indicated, and the use is non-commercial. See: http://creativecommons.org/licenses/by-nc/4.0/.

\section{NOTES}

1. Department of Health \& Department of Education (2017), "Transforming Children and Young People's Mental Health Provision: A Green Paper (Cm 9523)." Accessed March 7, 2017. https://assets.publishing.service.gov.uk/government/uploads/system/uploads/ attachment_data/file/664855/Transforming_children_and_young_people_s_mental_ health_provision.pdf

2. Nancy R Gee (2018), "Research methods used to consider the impact of HAl on older adults' health", Animals in Our Lives: Multidisciplinary approaches to the study of human-animal interactions, University of Sydney, Australia, 2018.

3. John Bradshaw (2018), The Animals Among Us: The New Science of Anthrozoology. Great Britain (Allen Lane): Penguin Books, 2018.

4. Peggy McCardle et al. (2011), How Animals Affect Us. London, England: American Psychological Association, 2011.

5. Nancy R Gee et al. (2010), "Preschoolers make fewer errors on an object categorization task in the presence of a dog", Anthrozoos 23, no. 3 (2010): 223-30. 
6. Nancy R Gee et al. (2012), "The presence of a therapy dog results in improved object recognition performance in preschool children", Anthrozoos 25, no. 3 (2012): 289-300.

7. Nancy R Gee et al. (2007), "The role of therapy dogs in speed and accuracy to complete motor skills tasks for preschool children", Anthrozoos 20, no. 4 (2007):37486.

8. Andrew Causey (2017), Drawn to See: Drawing as an Ethnographic Method, vol. 2017. Canada, New York USA, Plymouth UK: University of Toronto Press, 2017.

9. N Sousanis (2015), Unflattening. London: Harvard Press, 2015.

10. Paul Klee (2018), The Notebooks of Paul Klee: The Thinking Eye, vol 1. London: Lund Humphries, 1961.

11. Alexandra E Sexton et al. (2017), "Better than text? Critical reflections on the practices of visceral methodologies in human geography", Geoforum 82 (2017): 200-1.

12. Donna Haraway (1988), "Situated knowledge: the science question in feminism and the privilege of partial perspective", Feminist Studies 14, no. 3 (1988): 575-99.

13. N Katherine Hayles (2017), Unthought. Chicago and London: University of Chicago Press, 2017.

14. Sigrid Schmitz and Grit Höppner (2014), "Neurofeminism and feminist neuroscience: a critical review of contemporary brain research", Frontiers in Human Neuroscience 8 (2014): 546

15. Karen Barad (2007), Meeting the Universe Halfway: Quantum Physics and the Entanglement of Matter and Meaning. Durham and London: Duke University Press, 2007.

16. Will Eisner (2006), Comics and Sequential Art. New Jersey: Paramus, 2006.

17. Giles Deleuze and Felix Guattari (2013), A Thousand Plateaus. London and New York: Bloomsbury Academic, 2013.

18. David M Fetterman (2010), Ethnography. Step-by-Step, vol. 17, 3rd edn London, UK: Sage, 2010.

19. Colwyn Trevarthern (2011). "The Connected Baby DVD", In The Rythm and Musicality of Communication, Zeedyk SD and Robertson J, (Producer) 2011 mins.

20. R M Ryan and E L Deci (2000), "Self-determination theory and the facilitation of intrinsic motivation, social development and well-being", American Psychologist 55, no. 1 (2000): 68-78.

21. Monique Lhussier (2009), Quality of Life: Nomadological Insights. A Nomadic Exploration of quality of Life in Long-Term Conditions. Germany: VDM Publishing House, 2009

22. Affrica Taylor and Miriam Giugni (2012), "Common Worlds: reconceptualising inclusion in early childhood communities", Contemporary Issues in Early Childhood 13, no. 2 (2012): 108-19.

23. Donna Haraway (2008), When Species Meet. Minneapolis: University of Minnesota Press, 2008.

24. James J Gibson (1979), The Ecological Approach to Visual Perception. New Jersey: Lawrence Elbaum, 1979.

25. Sarah Pink (2015), Doing Sensory Ethnography, 2nd ed. London, UK: Sage, 2015.

26. Grace Cho (2008), Haunting the Korean Disapora: Shame, Secrecy and the Forgotten War. Minneapolis: University of Minesota, 2008.

27. Britta. T Knudsen and Carsten Stage (2015), Affective Methodologies: Developing Cultural Research Strategies for the Study of Affect. Hampshire, UK and New York USA: Palgrave Macmillan, 2015.

28. Nigel Thrift (2007), Non-representational Theory: Space, Politics, Affect. London and New York: Routledge. Taylor and Francis Group, 2008.

29. Ian Buchanan (2014), "Assemblage theory and schizoanalysis", Panoptikum 13, no. 20 (2014): 115-25.

30. Ian Hague (2014), Comics and the Senses: A Multi-sensory Approach to Comics and Graphic Novels. London and New York: Routledge, Taylor and Francis Group, 2014.

31. Scott McCloud (1994), Understanding Comics; The Invisible Art. New York: Harper Perennial, 1994.

32. OECD (2015), PISA 2015 Results (Volume III): Students' Well-Being. Paris: OECD, 2017. https://doi.org/10.1787/9789264273856-en

33. Derek P McCormack (2013), Refrains for Moving Bodies: Experience and Experiment in Affective Spaces. Durham and London: Duke University Press, 2013.

34. Lucy Connolly and John G Cullen (2018), "Animals and organisations: an ethic of care framework". Organization \& Environment 31, no. 4: 406-24, doi: 10.1177/1086026617712975.

35. Jane Bennett (2010), Vibrant Matter: A Political Ecology of Things. USA: Duke University Press Durham and London, 2010.

36. J Ash and L Gallacher (2010), "Becoming attuned: objects, affects and embodied methodology". in Journal of Organizational Ethnography, vol. 4, edited by Perry M and Medina CL, 356-66, 2010
37. Lesley Gallacher and Michael Gallagher (2008), "Methodological immaturity in childhood research? Thinking through 'participatory methods'", Childhood 15, no. 4 (2008): 499-516

38. James Ash (2017), "Visceral methodologies, bodily style and the non-human," Geoforum 82 (2017): 2006-07.

39. David José Menor-Campos et al. (2018), "Belief in Animal Mind among Spanish Primary School Children." Anthrozoos 31, no. 5 (2018): 599-614.

\section{BIBLIOGRAPHY}

Ash, J, and Gallacher, L. "Becoming attuned: Oobjects, affects and embodied methodology." In Journal of Organizational Ethnography, vol. 4, edited byPerry M, and Medina CL, 356-66, 2010.

Ash, James. "Rethinking affective atmospheres: technology, perturbation and space times of the non-human." Geoforum 49 (2013): 20-8.

Ash, James. "Visceral methodologies, bodily style and the non-human." Geoforum 82 (2017): 206-7.

Barad, Karen. Meeting the Universe Halfway: Quantum Physics and the Entanglement of Matter and Meaning. Durham and London: Duke University Press, 2007.

Bennett, Jane. Vibrant Matter: A Political Ecology of Things. USA: Duke University Press Durham and London, 2010.

Bradshaw, John. The Animals Among Us: The New Science of Anthrozoology. Great Britain (Allen Lane): Penguin Books, 2018.

Buchanan, lan. "Assemblage theory and schizoanalysis." Panoptikum 13, no. 20 (2014): $115-25$.

Causey, Andrew. Drawn to See: Drawing As An Ethnographic Method, vol. 2017. Canada, New York USA, Plymouth UK: University of Toronto Press, 2017.

Cho, Grace. Haunting the Korean Disapora: Shame, Secrecy and the Forgotten War. Minneapolis: University of Minesota, 2008.

Connolly, Lucy, and John G, Cullen. "Animals and organisations: an ethic of care framework." Organization \& Environment 31, no. 4 (2018): 406-24.

Deleuze, Giles, and Felix, Guattari. A Thousand Plateaus. London and New York: Bloomsbury Academic, 2013.

Department of Health \& Department of Education. "Transforming Children and Young People's Mental Health Provision: a Green Paper (Cm 9523)", 2017. Accessed $7 \mathrm{Mar}$ 2017. https://assets.publishing.service.gov.uk/government/uploads/system/uploads/ attachment_data/file/664855/Transforming_children_and_young_people_s_mental_ health_provision.pdf

Edensor, Tim. "Walking in rhythms: place, regulation, style and the flow of experience." Visual Studies 25, no. 1 (2010): 69-79.

Eisner, Will. Comics and Sequential Art. New Jersey: Paramus, 2006.

Fetterman, David M. Ethnography. Step-by-Step, vol. 17, 3rd edn. London, UK: Sage, 2010.

Gallacher, Lesley, and Michael, Gallagher. "Methodological Immaturity in Childhood Research? Thinking through 'participatory methods'." Childhood 15, no. 4 (2008): 499-516.

Gee, Nancy R, Shelly L, Harris, and Kristina L, Johnson. "The role of therapy dogs in speed and accuracy to complete motor skills tasks for preschool children." Anthrozoös 20, no. 4 (2007): 375-86.

Gee, Nancy R., Meredith T. Church, and Christie L. Altobelli. "Preschoolers make fewer errors on an object categorization task in the presence of a dog." Anthrozoös 23, no. 3 (2010), no. : 223-30.

Gee, Nancy R, Jonell M, Belcher, Jennifer L, Grabski, Michael, DeJesus, and Whitney, Riley. "The presence of a therapy dog results in improved object recognition performance in preschool children." Anthrozoös 25, no. 3 (2012), no. : 289-300.

Gee, Nancy R. "Research methods used to consider the impact of HAl on older adults' health." Animals in Our Lives: Multidisciplinary approaches to the study of humananimal interactions: University of Sydney, Australia, 2018.

Gibson, James J. The Ecological Approach to Visual Perception. New Jersey: Lawrence Elbaum, 1979.

Haque, Ian. Comics and the Senses: A Multi-sensory Approach to Comics and Graphic Novels. London and New York: Routledge, Taylor and Francis Group, 2014.

Haraway, Donna. "Situated Knowledges: the science question in feminism and the privilege of partial perspective." Feminist Studies 14, no. 3 (1988): 575-99.

Haraway, Donna. When Species Meet. Minneapolis: University of Minnesota Press, 2008.

Hayles, N Katherine. Unthought. Chicago and London: University of Chicago Press, 2017.

Klee, Paul. Notebooks of Paul Klee: The Thinking Eye, vol. 1. London: Lund Humphries, 2018. https://archive.org/stream/PaulKleeNotebooksVol1TheThinkingEye/Paul_Klee_ Notebooks_Vol_1_The_Thinking_Eye_djvu.txt

Knudsen, Britta. T, and Carsten, Stage. Affective Methodologies: Developing Cultural Research Strategies for the Study of Affect. Hampshire, UK and New York USA: Palgrave Macmillan, 2015.

Lhussier, Monique. Quality of Life: Nomadological Insights. A Nomadic Exploration of quality of Life in Long-Term Conditions. Germany: VDM Publishing House, 2009.

Lorimer, Jamie. Non-Human Charisma. Environment and Planning D, vol. 25, 911-32: Society and Space, 2007.

McCardle, Peggy, Sandra, McCune, James A, Griffin, and Valerie, Maholmes. How Animals Affect Us. London, England: American Psychological Association, 2011.

McCloud, Scott. Understanding Comics; The Invisible Art. New York: Harper Perennial, 1994. 
McCormack, Derek P. Refrains for Moving Bodies: Experience and Experiment in Affective Spaces. Durham and London: Duke University Press, 2013.

Menor-Campos, David José, Roxanne, Hawkins, Joanne, Williams, J, Hawkins. "Belief in animal mind among Spanish primary school children." Anthrozoös 31, no. 5 (2018): 599-614.

OECD. PISA 2015 Results (Volume III) 2015: Students' Well-Being. Paris: OECD, 2015. https://doi.org/10.1787/9789264273856-en

Pink, Sarah. Doing Sensory Ethnography, 2nd edn. London, UK: Sage, 2015.

Ryan, R M, and E L, Deci. "Self-determination theory and the facilitation of intrinsic motivation, social development, and well-being." American Psychologist 55, no. 1 (2000): 68-78.

Schmitz, Sigrid, and Grit, Höppner. "Neurofeminism and feminist neurosciences: a critical review of contemporary brain research." Frontiers in Human Neuroscience 8 (2014): 546.
Sexton, Alexandra E, Allison, Hayes-Conroy, Elizabeth L, Sweet, Mara, Miele, James, Ash, E, Hayes-Conroy, and Allison, Sweet. "Better than text? Critical reflections on the practices of visceral methodologies in human geography." Geoforum 82 (2017): 200-1.

Sousanis N. Unflattening. London: Harvard Press, 2015.

Taylor, Affrica, and Miriam, Giugni. "Common worlds: reconceptualising inclusion in early childhood communities." Contemporary Issues in Early Childhood 13, no. 2 (2012): 108-19.

Thrift, Nigel. Non-representational Theory: Space, Politics and Affect. London: Routledge, 2007.

Trevarthern, Colwyn. "The Connected Baby DVD." In The Rhythm and Musicality of Communication, Zeedyk DS, Robertson J, (Producer), 2011 